\title{
UTILIZAÇÃO DE ENZIMAS EXÓGENAS NA NUTRIÇÃO DE PEIXES - REVISÃO DE LITERATURA
}

\author{
Veruska Dilyanne Silva Gomes ${ }^{1}$ \\ José Humberto Vilar da Silva ${ }^{2}$ \\ Cácio Ribeiro Cavalcanti ${ }^{3}$ \\ Sthelio Braga da Fonseca ${ }^{4}$ \\ José Jordão Filho \\ Manuel Rosa da Silva Neto ${ }^{5}$ \\ Felipe Bonifácio da Silva ${ }^{6}$
}

GOMES, V. D. S.; SILVA, J. H. V. da; CAVALCANTI, C. R.; FONSECA, S. B. da; JORDÃO FILHO, J.; SILVA NETO, M. R. da; SILVA, F. B. da. Utilização de enzimas exógenas na nutrição de peixes - revisão de literatura. Arq. Ciênc. Vet. Zool. UNIPAR, Umuarama, v. 19, n. 4, p. 259-264, out./dez. 2016.

RESUMO: As enzimas exógenas são adicionadas nas rações para não ruminantes com o objetivo de remover ou diminuir fatores antinutricionais dos alimentos, aumentar a digestibilidade das rações, reduzir a viscosidade dos alimentos, auxiliar na atividade das enzimas endógenas e atuar em substratos que não são degradados pelas enzimas produzidas pelos peixes. Dessa forma, a presente revisão visa a apresentar as enzimas digestivas em peixes, os bioprocessos para produção de enzimas, alguns resultados obtidos com a adição de enzimas exógenas e a influência do uso de enzimas sobre a qualidade da água de cultivo. Diversos tipos de fungos, bactérias e leveduras podem produzir enzimas, por meio de técnicas de recombinação de DNA e mutações. Os peixes possuem estreita relação com o meio no qual estão inseridos, por isso, alterações nos parâmetros físico-químicos da água podem influenciar o crescimento, peso, saúde e reprodução destes. Dessa forma, o uso de enzimas exógenas na alimentação animal pode contribuir para a diminuição do impacto ambiental causado pela produção animal, pois, atuam aumentando a digestibilidade das rações e de nutrientes poluentes como fósforo e nitrogênio quando as enzimas específicas para estes substratos são adicionadas às rações, como a fitase e protease. $\mathrm{O}$ uso da biotecnologia, por meio da utilização de enzimas exógenas ou complexos enzimáticos na nutrição de peixes, melhora o desempenho zootécnico, aumenta a digestibilidade das rações e contribui na redução da excreção de nutrientes no ambiente aquático, interferindo de forma positiva na qualidade da água no sistema de produção.

PALAVRAS-CHAVE: Aditivos. Espécies Piscícolas. Suplementação enzimática.

\section{USE OF EXOGENOUS ENZYME IN FISH NUTRITION - LITERATURE REVIEW}

\begin{abstract}
Exogenous enzymes are added in non-ruminant feed aiming to remove or reduce antinutritional factors in feed, increase digestibility, reduce feed viscosity, assisting the endogenous enzyme activities and act on substrates that are not degraded by enzymes produced by the fish. Therefore, this review aims to present the digestive enzymes in fish, the enzyme production bioprocesses, some results obtained with the addition of exogenous enzymes and the influence of using enzymes in the quality of cultivation water. Various types of fungi, bacteria and yeast can produce enzymes through recombinant DNA techniques and mutations. Fish have close relation with the medium in which they are inserted; therefore, changes in the water physico-chemical parameters can influence their growth, weight, health and reproduction. Therefore, the use of exogenous enzymes in animal nutrition can contribute to reducing the environmental impact of animal production, and thus act by increasing the digestibility of nutrients and pollutants such as phosphorus and nitrogen when specific substrates for these enzymes are added to the feed, such as phytase and protease. The use of biotechnology in the use of exogenous enzymes or enzyme complexes in fish nutrition improves animal performance, increases feed digestibility and contributes to reducing the excretion of nutrients in the aquatic environment, positively interfering in the water quality in the production system.
\end{abstract}

KEYWORDS: Additives. Enzyme supplementation. Fish species.

\section{USO DE ENZIMAS EXÓGENAS EN NUTRICIÓN DE PECES - REVISIÓN DE LITERATURA}

RESUMEN: Las enzimas exógenas son añadidas a las dietas de no rumiantes, con el objetivo de eliminar o reducir factores anti nutricionales de alimentos, aumentar la digestibilidad de los piensos, reducir la viscosidad de los alimentos, ayudar en la actividad de las enzimas endógenas y actuar en sustratos que no se degradan por las enzimas producidas por los peces. Así, esta revisión busca presentar las enzimas digestivas en peces, los bioprocesos para la producción de enzimas, algunos

DOI: https://doi.org/10.25110/arqvet.v19i4.2016.6106

${ }^{1}$ Zootecnista, Ma., Doutoranda em Zootecnia.Universidade Federal da Paraíba - CCHSA, Campus III, Departamento de Ciência Animal, Bananeiras, CEP 58240-000. Email: veruska_sgomes@yahoo.com.br

${ }^{2}$ Professor Doutor, Universidade Federal da Paraíba

${ }^{3}$ Zootecnista, Mestre em Tecnologia Agroalimentar, UFPB.

${ }^{4}$ Professor Doutor, Universidade Federal de Campina Grande.

${ }^{5}$ Biólogo, Mestrando em Zootecnia, UFPB.

${ }^{6}$ Graduando em Agroindústria, UFPB. 
resultados obtenidos con la adición de enzimas exógenas y la influencia del uso de enzimas en la calidad del agua del estanque. Varios tipos de mohos, bacterias y levaduras pueden producir enzimas, mediante técnicas de ADN recombinante y mutaciones. Los peces tienen estrecha relación con el medio ambiente en que viven, por eso, alteraciones en los parámetros físico-químicos del agua pueden influir en el crecimiento, peso, salud y reproducción de estos. Por lo tanto, el uso de enzimas exógenas en la alimentación animal puede contribuir a reducir el impacto ambiental causado por la producción animal, pues, actúan aumentando la digestibilidad de piensos y nutrientes contaminantes como el fósforo y el nitrógeno cuando las enzimas específicas para estos sustratos son añadidas a piensos, como la fitasa y proteasa. El uso de la biotecnología, mediante el uso de enzimas exógenas o complejos de enzimas en la alimentación de peces, mejora el rendimiento zootécnico, incrementa la digestibilidad de pienso y contribuye en la reducción de la excreción de los nutrientes en el medio acuático, interfiriendo positivamente en la calidad del agua en el sistema de producción.

PALABRAS CLAVE: Aditivos. Especies de peces. Suplementación de enzimas.

\section{Introdução}

A produção mundial de organismos aquáticos, com destaque para a produção de peixes, tem apresentado índices crescentes e promissores para o setor (FAO, 2012). Tornando a atividade atrativa para produtores em diversas escalas comerciais.

No entanto, a intensificação da produção, caracterizada pela maior densidade de estocagem, diminuição do tempo de cultivo e maior ganho em peso dos animais, exige que estes sejam alimentados com rações visando atender as exigências nutricionais que outrora eram supridas apenas com alimentação natural. Porém, alguns fatores podem influenciar as exigências nutricionais do animal e também a disponibilidade dos nutrientes presentes nas rações. Estes fatores estão relacionados com a fase de crescimento, manejo, fisiologia do animal, aspectos físico-químicos da água e, principalmente, o tipo de alimento e a proporção em que este se encontra na ração (FURUYA, 2010).

A produção de rações para organismos aquáticos crescem de forma notável. Segundo dados do Sindicato Nacional da Indústria de Alimentação Animal - Sindirações (2013) foram produzidas cerca de 700 mil toneladas de ração para organismos aquáticos, das quais estima-se que mais de 660 mil toneladas foram produzidas para atender o setor de cultivo de peixes visando atender a expressiva produção nacional de pescado.

O uso de enzimas exógenas em dietas para animais não ruminantes viabiliza benefícios como a possibilidade de empregar ingredientes que possuem nutrientes pouco disponíveis aos animais, por estes não produzirem as enzimas necessárias; a redução do nível de alguns nutrientes como fósforo e nitrogênio nas fezes, diminuindo assim a quantidade desses elementos no meio atuando como potenciais meios de contaminação do ambiente (CAMPESTRINI; SILVA; APPELT, 2005).

Alguns estudos comprovam que a utilização de enzimas ou complexos enzimáticos melhora a digestibilidade de rações tanto a base de milho e soja (OLIVEIRA, 2007) como também, de ingredientes alternativos com alta viscosidade, como o farelo de trigo (GUIMARÃES et al, 2009) e o triticale (TACHIBANA et al., 2010).

Desta forma, a presente revisão visa apresentar as enzimas digestivas em peixes, os bioprocessos para produção de enzimas, alguns resultados obtidos com a adição de enzimas exógenas e a influência do uso de enzimas sob a qualidade da água de cultivo.

\section{Desenvolvimento}

\section{Enzimas digestivas em peixes de interesse comercial}

As enzimas são, em sua maioria, proteínas indispensáveis para a realização dos processos metabólicos nos seres vivos, pois, as reações bioquímicas que acontecem no organismo são catalisadas por estas. As enzimas aumentam a velocidade das reações diminuindo a energia de ativação sem alterarem o equilíbrio químico; são específicas, atuam por meio de sítio ativo, apenas em determinado substrato; são sensíveis às mudanças de $\mathrm{pH}$ e temperatura do meio, havendo assim, um limiar ótimo no qual ocorre máxima atividade (NELSON; COX, 2014).

Nos peixes, após eclosão e absorção do vitelo, a larva está pronta para nutrir-se com alimentação exógena, no entanto, o trato gastrointestinal é curto e pouco desenvolvido. Devido a isso, elas utilizam as enzimas de presas vivas na digestão (BALDISSEROTTO, 2009). Justificando assim a utilização de alimento vivo (micro vermes, náuplios de artêmia) no início da vida dos peixes.

Os complexos enzimáticos e enzimas exógenas adicionados na formulação de rações para peixes podem ser enquadradas em duas categorias abrangentes: enzimas que possuem produção endógena, mas são adicionadas visando suplementar a atividade enzimática no organismo (amilase, protease, lipase entre outras) e enzimas que não são sintetizadas pelos peixes (xilanases, $\beta$-glucanases, celulase, fitase entre outros).

A utilização de rações balanceadas e inclusão de aditivos pode ser uma alternativa viável implantada na produção de peixes, pois, a suplementação com enzimas exógenas em dietas micro particuladas para pós-larvas de Pacu (Piaractus mesopotamicus) apresentou resultados positivos quanto ao peso médio final, crescimento e sobrevivência dos animais (TESSER, 2006).

As enzimas são adicionadas nas rações para não ruminantes com o objetivo de remover ou diminuir fatores antinutricionais dos alimentos (como os polissacarídeos não amiláceos), aumentando a digestibilidade das rações; reduzindo a viscosidade dos alimentos, auxiliando a atividade das enzimas endógenas e atuando em substratos que não são degradados por enzimas endógenas, como a celulose (CLEOPHAS; HARTINGSVALDT; SOMERS, 1995). (Tabela 1). 
Tabela 1: Enzimas, modo de atuação e substrato das enzimas na digestão de nutrientes em dietas para não ruminantes.

\begin{tabular}{llc}
\hline Enzima digestiva & Modo de atuação na digestão & Substrato \\
\hline Amilase & Suplementa enzimas endógenas & Amido \\
Celulase & Não sintetizada pelo organismo & Celulose \\
Fitase & $\begin{array}{l}\text { Auxilia na disponibilidade de } \\
\text { fósforo presente nos vegetais }\end{array}$ & Ácido fítico \\
$\beta$-glucanases & Redução da viscosidade das rações & $\beta$-glucanos \\
Pectinase & Redução da viscosidade das rações & Pectinas \\
Xilanase & Redução da viscosidade das rações & Arabinoxilanos \\
Protease & Suplementa enzimas endógenas & Proteína \\
\hline CLEOPHAS; HARTINGSVALDT; SOMERS (1995). &
\end{tabular}

O uso combinado de enzimas exógenas na forma de complexos enzimáticos possui maior comercialização no mercado agropecuário, visto que, as rações são formuladas com diversos ingredientes que por sua vez apresentam composição variável e necessitam de enzimas diversas para degradar seus compostos (CAMPESTRINI; SILVA; APPELT, 2005).

A produção endógena de amilase em espécies de peixes onívoras é eficiente no intestino destes animais, apresentando em algumas espécies de peixes, maior atividade nos cecos e intestino proximal (BALDISSEROTTO, 2009). A inclusão de $0,05 \%$ de amilase exógena em rações para juvenis de Tambaqui (Colossoma macropomum) possibilitou melhor desempenho zootécnico dos peixes. No entanto, com a utilização de níveis superiores houve redução no desempenho dos animais. Os autores atribuem os resultados à possibilidade de ocorrer uma excessiva sobrecarga do fígado devido aos processos metabólicos, prejudicando o crescimento e ganho em peso dos peixes (NUNES et al., 2006).

A digestão de proteína inicia com a hidrólise, no estômago, pela ação dos sucos gástricos e da enzima pepsina. $\mathrm{O}$ intestino delgado representa o maior sítio de digestão, pela ação de proteases pancreáticas e absorção de proteínas (SWENSON, 1988). Em peixes que não apresentam estômago, o início da hidrólise e digestão de proteínas é realizada pela tripsina pancreática (BALDISSEROTTO, 2009).

A atividade enzimática nos peixes pode ser regulada pela quantidade e composição da ração. Jundiás (Rhamdia quelen) alimentados com dietas suplementadas em níveis com aminoácido apresentaram atividade da protease na região anterior do intestino, responsiva à inclusão dos aminoácidos (UNGAR et al., 2009). A temperatura da água também afeta a atividade enzimática, visto que os peixes são animais ectotérmicos (MOURA; OLIVEIRA; LANNA, 2009).

A inclusão de enzimas visando suplementar as produzidas pelo organismo tem apresentado efeitos positivos na nutrição de peixes. Soares et al. (2008), em experimento avaliando o efeito da inclusão de protease exógena em ração para tucunaré (Cichla sp.) relataram que a inclusão da enzima, em $0,10 \%$, melhorou a conversão alimentar, ganho em peso e taxa de crescimento específico (ganho de peso em função de um determinado intervalo de tempo).

A utilização de complexos enzimáticos pode ser justificada por permitir que diversas enzimas atuem de forma simultânea e complementar possibilitando maior disponibilidade de proteína e energia na dieta e, consequentemente, maior aproveitamento destes nutrientes pelos peixes (OLIVEIRA, 2007).
A disponibilidade de nutrientes presentes em um determinado ingrediente pode ser influenciada pela formação de complexos naturais. Algumas sementes de oleaginosas e leguminosas apresentam estes complexos, como o fitato ou ácido fítico que armazena fósforo nestes vegetais. Os animais monogástricos não são capazes de metabolizar o fitato por não produzirem a enzima fitase (JACKSON; LI, 1996).

Em juvenis de tambaqui (Colossoma macropomum), a suplementação com fitase influenciou de forma positiva o ganho de peso, conversão alimentar aparente e taxa de crescimento específico (MENDONÇA et al., 2012).

Uma quantidade considerável do fósforo presente nos ingredientes de origem vegetal não está prontamente disponível, havendo a necessidade de sua inclusão com a finalidade de melhorar a absorção do fósforo. Esta enzima é produzida por bactérias, fungos e leveduras. O fitato, além de se ligar ao fósforo, forma quelatos com cátions (cálcio, ferro, magnésio, sódio) e dificulta a absorção de aminoácidos (CAMPESTRINI; SILVA; APPELT, 2005). Entretanto os resultados ainda são controversos. Bock et al. (2007) não encontrou efeito positivo no desempenho de Tilápias do Nilo (Oreochromis niloticus), na fase de crescimento, alimentados com dietas contendo fitase. Efeito semelhante foi observado no desempenho de Carpa Húngara (Cyprinus carpio). A inclusão de fitase aumentou o teor de cinzas e diminuiu o teor de extrato etéreo da carcaça destes animais, que possuem quantidade considerável de gordura (ROCHA et al., 2010).

\section{Bioprodução de enzimas digestivas}

A biotecnologia moderna promove impacto positivo na nutrição animal possibilitando atender de forma eficiente os requerimentos fisiológicos, causando impacto significativo também na saúde e bem-estar dos animais. Neste âmbito, a biotecnologia pode ser descrita como o uso de organismos vivos ou parte deles, para a produção de bens e serviços (ROCHA, 2008).

Nos últimos anos, tem sido notável o avanço na produção e utilização de enzimas exógenas, devido ao conhecimento dos substratos alvos e tecnologias microbianas visando extração eficiente das enzimas (BEDFORD; PARTRIDGE, 2011).

Para utilização na alimentação animal, no final da década de 1980, a produção de enzimas atingiu escala comercial. Diversos tipos de fungos, bactérias e leveduras podem produzir enzimas, por meio de técnicas de recombinação de DNA e mutações. A fitase é produzida por alguns fungos $\mathrm{As}$ pergillus sp. A enzima celulase é produzida durante atividades fermentativas de Trichoderma viride (CAMPESTRINI; SILVA; APPELT, 2005).

Nos últimos anos, técnicas para a produção de complexos enzimáticos vêm sendo desenvolvidas com sucesso. A fermentação em estágio sólido (solid state fermantation SSF) consiste em permitir o crescimento de fungos em um substrato sólido como os farelos e farinhas provenientes dos grãos. Este processo elimina as perdas do processo comumente utilizado, pois, não existe a necessidade de remoção de líquidos e posterior mistura à substância veículo, além de haver a possibilidade de modificar a composição e teor de enzimas no complexo, modificando o substrato onde o fungo é inserido. Isso permite que o produto final da fermentação 
apresente uma composição enzimática adequada aos ingredientes presentes na ração onde este será incorporado como aditivo (ROBISON; NIGAN, 2003).

\section{Resultados da adição de enzimas na nutrição de peixes}

A utilização de enzimas visando melhorar o desempenho dos animais alimentados com cereais tem a finalidade de reduzir fatores antinutricionais que estão presentes na parede celular dos grãos em quantidades variáveis dificultando a digestão e absorção de nutrientes, como os polissacarídeos não amiláceos (PNAs) visto que os monogástricos não possuem enzimas específicas para determinados substratos, surgindo a necessidade da adição nestas rações (BEDFORD; PARTRIDGE, 2011).

As enzimas são adicionadas em rações cuja composição contém quantidades consideráveis de PNA's visando suprir a deficiência em enzimas endógenas para este substrato (ALBINO; BÜNZEN; ROSTAGNO, 2007). Atualmente, pesquisas avaliando a inclusão de complexos enzimáticos, em rações para peixes à base de grãos com baixa viscosidade (milho e farelo de soja), tem observado resultados positivos no desempenho destes animais possibilitando uma utilização eficiente do amido e proteína (MOURA et al., 2012).

No entanto, a utilização de complexos enzimáticos apresenta resultados controversos. Signor et al. (2013), ao avaliarem a suplementação com complexo enzimático (amilase, protease, celulase, lipase, b-glucanase e fitase) em rações para o peixes ornamental japonês (Carassius auratus), não observaram diferenças significativas para o crescimento, ganho em peso e conversão alimentar. Igualmente, Kazerani e Shahsavani (2011) avaliando a inclusão de um complexo enzimático em dietas a base de farelo de trigo, soja e farelo de algodão, em rações para carpa (Cyprinus carpio) os autores verificaram que a inclusão do complexo não foi eficiente em proporcionar uma melhor conversão alimentar, crescimento e ganho em peso, apresentando resultados inferiores aos da dieta controle, quando adicionadas em excesso. Por outro lado, em dietas para Catfish Africano (Clarias gariepinus), suplementadas com o complexo enzimático composto por: xilanase, pentonases, amilase, hemicelulase, celulase, pectinases, celubiase e $\beta$-glucanase; foi observado que os animais alimentados com ração contendo o complexo enzimático obtiveram melhor conversão alimentar $(\mathrm{P}<0,05)$ quando suplementadas nos níveis de $0,05 \%$ e $0,075 \%$ (YILDIRIM; TURAN, 2010). De maneira similar, Moura et al. (2012) verificaram que em dietas para Tilápia do Nilo, a suplementação com complexo enzimático melhorou o peso final e ganho em peso dos animais.

Juvenis de Tilápia do Nilo alimentados com dietas à base de farelo de soja e milho com suplementação de complexo enzimático, apresentaram menor consumo de ração e melhor conversão alimentar quando suplementados com $0,066 \%$ e $0,099 \%$, não havendo efeito no ganho em peso (SIGNOR et al., 2010). Segundo os autores, a suplementação enzimática pode contribuir para a redução de custos com alimentação visto que houve redução do consumo e melhora na conversão alimentar, sem perdas no ganho em peso.

Como já relatado anteriormente, as enzimas são aditivos eficientes na redução de fatores antinutricionais possibilitando aumento da digestibilidade das rações (GUI-
MARÃES et al., 2009) como também aumento na biodisponibilidade, no intestino, de carboidratos menos complexos (MOURA et al., 2012).

Para o tambaqui (Colosssoma macropomum) alimentado com rações a base de milho, farinha de peixes, soja e farinha de trigo, a suplementação com complexo enzimático composto por amilase, protease, lipase e celulase melhorou a digestibilidade aparente total e digestibilidade da proteína quando adicionado ao nível de $0,05 \%$. O aumento da digestibilidade da proteína pode influenciar de forma positiva na redução da excreção de compostos nitrogenados no ambiente aquático, diminuindo assim o impacto ambiental causado pela deposição destes nutrientes sobre a qualidade da água de cultivo (SILVA et al., 2007).

Os PNA's aumentam a viscosidade das rações devido à sua capacidade de se ligar à água, formando um gel viscoso (SANTOS-JÚNIOR; FERKET; GRIMES, 2004), atuando de forma negativa ao interferir na interação entre enzima e substrato, dificultando a absorção de nutrientes pela mucosa intestinal. Os PNA's podem ser classificados em solúveis: pectinas, gomas, hemicelulose (é formada pelos xiloglucanos, arabinoxilanos, $\beta$-glucanos, D-xilanos, D-mananos entre outros); e insolúveis: celulose e lignina principalmente (TAVERNARI et al., 2008).

No entanto, as características físicas e químicas da fibra devem ser avaliadas, pois, a quantidade presente nas rações dependerá do processamento e das limitações fisiológicas e metabólicas das espécies de peixes. Dietas contendo níveis crescentes de fibra bruta para Tilápia do Nilo apresentaram efeito significativo na diminuição da digestibilidade da matéria seca, proteína bruta e do extrato etéreo mediante aumento no nível de fibra na dieta (LANNA et. al., 2004).

Para reduzir a capacidade de retenção de água dos PNA's evitando que haja um aumento na viscosidade do quimo no intestino, é necessário que enzimas atuem decompondo esses compostos complexos em partículas menores, auxiliando a digestão e melhorando a absorção de nutrientes (OPALINSKI, 2006).

A inclusão de um complexo enzimático em rações com ingredientes que apresentam altos níveis de PNA's como o farelo de trigo, nas rações melhorou o peso final, ganho em peso e aumentou os níveis de monossacarídeos no quimo de juvenis de Tilápia do Nilo. Os resultados obtidos podem ser justificados devido ao melhor aproveitamento energético do alimento, contribuindo para que a proteína não seja desviada para produção de energia e, por isso, seja mobilizada de forma eficiente para a formação de tecidos (MOURA et al., 2012).

\section{Influência da suplementação enzimática sobre a qualida- de do ambiente nos sistemas de produção de peixes}

Os peixes são animais ectodérmicos e possuem estreita relação com o meio no qual estão inseridos. Alterações nos parâmetros físico-químicos da água podem influenciar de maneira negativa o crescimento, peso, saúde, reprodução, funções orgânicas e muitas vezes podem ocasionar a morte destes animais, variando com o grau de tolerância da espécie (CYRINO et al., 2010). O fornecimento de rações formuladas com ingredientes cujos nutrientes podem estar indisponíveis aos animais contribuem para uma digestão e absorção 
ineficientes das rações pelos peixes fazendo com que a excreção de compostos poluentes aumente.

Os principais poluentes provenientes da excreção de animais são o fósforo e os compostos nitrogenados. Uma descarga excessiva destes compostos promove a proliferação e crescimento de algas promovendo a eutrofização do ambiente de cultivo (BOCK et al., 2007). O uso de enzimas exógenas na alimentação animal pode contribuir para a diminuição do impacto ambiental causado pela produção animal, pois, atuam aumentando a digestibilidade das rações e o aproveitamento destes nutrientes quando as enzimas próprias para estes substratos são adicionadas a ração, como a fitase e proteases (CAMPESTRINI; SILVA; APPELT, 2005). Em outros não ruminantes como frango de corte, o uso da fitase nas dietas viabiliza a redução de cálcio e fósforo sem que ocorram perdas no desempenho, na mineralização óssea e na energia metabolizável aparente corrigida pelo balanço de nitrogênio (SANTOS et al., 2011).

Em resumo, o fornecimento de rações formuladas com ingredientes cujos nutrientes podem estar indisponíveis aos animais contribuem para uma digestão e absorção ineficientes das rações pelos peixes fazendo com que a excreção de compostos poluentes aumente (Cyrino et al., 2010) (Figura 1).

Figura 1: Fluxograma do impacto, no ambiente de criação, da suplementação enzimática em dietas para peixes.

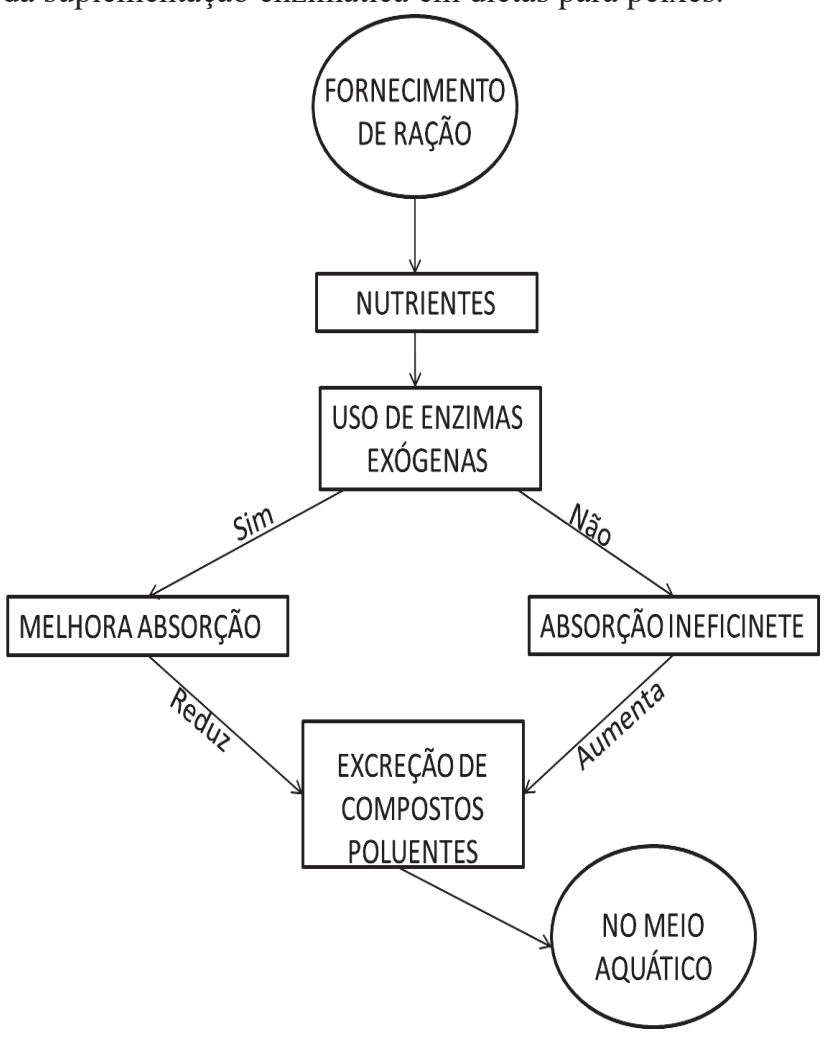

Fonte: Arquivo pessoal.

A inclusão de enzimas exógenas pode reduzir os níveis de fósforo inorgânico e viabilizar uma redução no teor de proteína bruta das rações para peixes (OLIVEIRA, 2007); diminuindo os impactos provocados pela deposição destes compostos na água dos sistemas de produção de organismos aquáticos e no ambiente natural (CYRINO et al., 2010 ).

\section{Considerações finais}

O uso da biotecnologia, por meio da utilização de enzimas exógenas ou complexos enzimáticos na nutrição de peixes, melhora o desempenho zootécnico, aumenta a digestiblidade das rações e contribui na redução da excreção de nutrientes no ambiente aquático, interferindo de forma positiva na qualidade da água dos sistemas de produção.

\section{Referencias}

ALBINO, L. F. T.; BÜNZEN, S.; ROSTAGNO, H. S. Ingredientes promotores de desempenho para frangos de corte. IN: SEMINÁRIO DE AVES E SUÍNOS, 7., Belo Horizonte. Anais... Belo Horizonte, p. 73-90, 2007.

BALDISSEROTTO, B. Fisiologia de peixes aplicada à piscicultura. 2 ed. Santa Maria: Editora da UFSM, 2009.

BEDFORD, M. R.; PARTRIDGE, G. G. Enzymes in farm animal nutrition. 2. ed. London: CAB Internationa, 2011.

BOCK, C. L. et al. Fitase em rações para tilápia-do-nilo na fase de crescimento. Revista Brasileira de Zootecnia, v. 36, n. 5, p. 1455-1461, 2007.

CAMPESTRINI, E.; SILVA, V. T. M. da; APPELT, M. D. Utilização de enzimas na alimentação animal. Revista Eletrônica Nutritime, v. 2, n. 6, p. 259-272, 2005.

CLEOPHAS, G. M. L.; HARTINGSVALDT, W. V.; SOMERS, W. A. C. Enzymes can play an important role in poultry nutrition. World Poutry, v. 11, n. 4, p. 12-15, 1995.

CYRINO, J. E. P. et al. A piscicultura e o ambiente - o uso de alimentos ambientalmente corretos em piscicultura.

Revista Brasileira de Zootecnia, v. 39, p. 68-87, 2010.

FAO (ORGANIZAÇÃO DAS NAÇÕES UNIDAS PARA AGRICULTURA E ALIMENTAÇÃO). The State of World Fisheries and Aquaculture. 2012. Rome, FAO. 2012.

FURUYA, W. M. Tabelas Brasileiras para a Nutrição de Tilápias. Toledo: GFM. 100p. 2010.

GUIMARÃES, I. G. et al. Digestibilidade aparente de rações contendo complexo enzimático para tilápia-donilo. Arquivos Brasileiros de Medicina Veterinária e Zootecnia, v. 61, n. 6, p. 1397-1402, 2009.

JACKSON, L.; LI, M. H.; ROBINSON, E. H. Use of microbial phytase in channel catfish Ictalurus punctatus diets to improve utilization of phytate phosphorus. Journal for the World Aquaculture Society, v. 27, n. 3, p. 309-313, 1996.

KAZERANI, H. R.; SHAHSAVANI, D. The effect of supplementation of feed with exogenous enzymes on the growth of common carp (Cyprinus carpio). Iranian Journal of Veterinary Research, v. 12, n. 2, p. 35, 2011. 
LANNA, E. A. T. et al. Digestibilidade aparente e trânsito gastrintestinal em Tilápia do Nilo (Oreochromis niloticus), em função da fibra bruta da dieta. Revista Brasileira de Zootecia, v. 33, n. 6, p. 2186-2192, 2004.

MENDONÇA, P. P. et al. Efeito da suplementação de fitase na alimentação de juvenis de tambaqui (Colossoma macropomum). Archivos de Zootecnia, v. 61, n. 235, p. 437-448. 2012.

MOURA, G. S. et al. Effects of enzyme complex SSF (solid state fermentation) in pellet diets for Nile tilapia. Revista Brasileira de Zootecnia, v. 41, n. 10, p. 2139-2143, 2012

MOURA, G. S.; OLIVEIRA, M. G. A.; LANNA, E. A. T. Atividade de tripsina no quimo de tilápia-tailandesa submetida a diferentes temperaturas da água. Revista Brasileira de Zootecnia, v. 38, n. 11, p. 2086-2090, 2009.

NELSON, D. L.; COX, M. M. Princípios de bioquímica de Lehninger. Porto Alegre: Artmed, 2014.

NUNES, E.S.S. et al. Enzimas digestivas exógenas na alimentação de juvenis de tambaqui. Pesquisa Agropecuária Brasileira, v.41, n.1, p.139-143, 2006.

OLIVEIRA, G. R. et al. Digestibilidade de nutrientes em ração com complexo enzimático para tilápia-do-nilo.

Revista Brasileira de Zootecnia, v. 36, n. 6, p. 1945-1952, 2007.

OPALINSKI, M. Utilização de enzima e soja integral em rações para frangos formuladas com ingredientes alternativos com base em aminoácidos digestíveis e totais. Dissertação de mestrado, Universidade Federal do Paraná, Curitiba. 2006.

ROBISON, T.; NIGAN, P. Biorector designfor protein enrichment of agricultural residues by solid state fermentation. Biochemical Engineering Journal, v. 13, p. 107-203. 2003.

ROCHA, C. B. et al. Fitase na dieta de alevinos de carpa húngara: desempenho e características de carcaça. Arquivos Brasileiros de Medicina Veterinária e Zootecnia, v. 62, n. 6, p. 1462-1468, 2010.

ROCHA, M. A. Biotecnologia na nutrição de cães e gatos. Revista Brasileira de Zootecnia, v.37, suplemento especial, p.42-48, 2008.

SANTOS, L. M. et al. Níveis de fósforo disponível e cálcio em rações suplementadas com fitase para frangos de corte nas fases de crescimento e final. Revista Brasileira de Zootecnia, v. 40, n. 11, p. 2486-2495, 2011.

SANTOS-JÚNIOR. A. A. et al. Dietary pentosanase supplementation of diets containing different qualities of wheat on growth performance and metabolizable energy of turkey poults. International Journal of Poultry Science, v. 3 , n. 1 , p. $33-45,2004$
SINDIRAÇÕES. Sindicato Nacional da Indústria de Alimentação Animal. Boletim informativo do setor. 2013. Disponível em: http://sindiracoes.org. br/wp-content/uploads/2013/12/sindiracoes-boletim dezembro_05122013_site.pdf. Acesso: 21 abr. 2014.

SIGNOR, A. A. et al. Desempenho de juvenis de Tilápiado-nilo alimentados com rações contendo complexo enzimático. Revista Brasileira de Zootecnia, v. 39, n. 5, p.977-983, 2010.

SIGNOR, A. A. et al. Complexo enzimático na dieta de alevinos de kinguio (Carassius auratus). Semina: Ciências Agrárias, v. 34, n. 3, p. 1381-1388, 2013.

SILVA, J.A.M. et al. Digestibilidade aparente de nutrientes e energia de ração suplementada com enzimas exógenas para juvenis de tambaqui (Colossoma macropomum Cuvier, 1818). Acta Amazônica, v. 37, n. 1, p.157-164, 2007.

SOARES, E.C. et al. Protease exógena em dietas para juvenis de tucunaré-paca (Cichla sp.). Revista Brasileira de Zootecnia, v. 37, n. 6, p. 971-976, 2008.

SWENSON, M. J. (Org.). Dukes, Fisiologia dos Animais domésticos. Rio de Janeiro: Guanabara Koogan, 1988. 799 p.

TACHIBANA, L. et al. Xilanase e $\beta$-glucanase na digestibilidade aparente de nutrientes do triticale pela Tilápia-do-nilo. Arquivos Brasileiros de Medicina Veterinária e Zootecnia, v. 62, n. 2, p. 445-452, 2010.

TAVERNARI, F. C. et al. Polissacarídeos não-amiláceo solúvel na dieta de suínos e aves. Revista eletrônica Nutritime, v. 5, n. 5, p. 673-689, 2008.

TESSER, M. B. et al. Suplementação de enzimas exógenas em dieta microparticulada para larvicultura do pacu.

Revista Brasileira de Zootecnia, v. 35, n. 6, p. 2211-2218, 2006.

UNGAR, A. B. at al. Efeito da adição de aminoácidos essenciais à dieta sobre a secreção de enzimas digestivas de jundiá Rhamdia quelen (Siluriformes, Pimelodidae). Acta Scientiarum Biological Sciences, v. 31, n. 1, p. 105-111, 2009.

YILDIRIM, Y.B.; TURAN, F. Effects of exogenous enzyme supplementation in diets on growth and feef utilization in African Catfish, Clarias gariepinus. Journal of Animal and Veterinary Advances, v. 9, n. 2, p.327-331, 2010. 